\title{
Reclassification of Lactobacillus kefirgranum Takizawa et al. 1994 as Lactobacillus kefiranofaciens subsp. kefirgranum subsp. nov. and emended description of $L$. kefiranofaciens Fujisawa et al. 1988
}

\author{
M. Vancanneyt, ${ }^{1}$ J. Mengaud, ${ }^{2}$ I. Cleenwerck, ${ }^{1}$ K. Vanhonacker, ${ }^{1}$ B. Hoste, ${ }^{1}$ \\ P. Dawyndt, ${ }^{3}$ M. C. Degivry, ${ }^{2}$ D. Ringuet, ${ }^{2}$ D. Janssens ${ }^{1}$ and J. Swings ${ }^{1,3}$ \\ ${ }^{1,3}{ }^{B C C M} / L M G$ Bacteria Collection ${ }^{1}$ and Laboratory of Microbiology ${ }^{3}$, Ghent University, Ghent, \\ Belgium \\ ${ }^{2}$ DANONE Vitapole, Vitavaleur, Palaiseau, France
}

\author{
Correspondence \\ marc.vancanneyt@ugent.be
}

\begin{abstract}
Fourteen homofermentative lactic acid bacteria that were isolated from kefir grains and kefir fermented milks were assigned to either Lactobacillus kefiranofaciens or Lactobacillus kefirgranum, based on their characteristic morphotypes, phenotypic features and SDS-PAGE profiles of whole-cell proteins. Further genotypic analyses on representative strains from both taxa demonstrated that $L$. kefiranofaciens and $L$. kefirgranum share $100 \% 16$ S rDNA sequence similarity and belong phylogenetically to the Lactobacillus acidophilus species group. DNA-DNA binding values of $>79 \%$ and analogous DNA G $+C$ contents of 37-38 mol\% showed that the strains studied belonged to one species: $L$. kefirgranum is a later synonym of $L$. kefiranofaciens. An emended description is proposed for $L$. kefiranofaciens. Due to the specific morphological and biochemical characteristics of these taxa in kefir grain formation, it is proposed that L. kefirgranum should be reclassified as $L$. kefiranofaciens subsp. kefirgranum subsp. nov.
\end{abstract}

Kefir is a traditional dairy product that originated from the Caucasus. It is obtained by fermentation of milk at room temperature, using kefir grains as starters. Kefir grains are a naturally immobilized starter; they are made of a complex association of micro-organisms that are more or less embedded in a biopolymer called kefiran. During the last 40 years, many studies have focused on analysis of kefir grain microflora. It contains Gram-positive homofermentative and heterofermentative lactic acid bacteria (lactobacilli, lactococci and leuconostocs), Gram-negative acetic acid bacteria (Acetobacter) and both lactose-fermenting (Kluyveromyces marxianus and Kluyveromyces lactis) and non-fermenting (mostly Saccharomyces species) yeasts (Hirota, 1987; Toba, 1987; Halle, 1992; Halle et al., 1994). Four novel Lactobacillus species were identified in the kefir microflora: Lactobacillus kefiri (Kandler \& Kunath, 1983), Lactobacillus kefiranofaciens (Fujisawa et al., 1988) and, more recently, Lactobacillus parakefiri and Lactobacillus kefirgranum (Takizawa et al., 1994). L. kefiranofaciens and

Published online ahead of print on 17 October 2003 as DOI 10.1099/ ijs.0.02912-0.

The GenBank/EMBL/DDBJ accession numbers for the $16 \mathrm{~S}$ rDNA sequences of Lactobacillus kefiranofaciens LMG $19149^{\top}$ and R-14703 and Lactobacillus kefirgranum LMG $15132^{\top}$ and R-12929 are AJ575259, AJ575260, AJ575261 and AJ575262, respectively.
L. kefirgranum are both homofermentative lactobacilli that seem to be major microbial constituents of kefir grains. L. kefiranofaciens strains form very viscous colonies and are responsible for the formation of kefiran, one of the major polysaccharides that forms kefir grains (Mukai et al., 1990; Yokoi et al., 1991).

In the process of a biodiversity study of several kefir grains and kefir fermented milks, a large number of bacterial strains were isolated on MLR medium (milk-based agar) after anaerobic incubation at $30^{\circ} \mathrm{C}$. MLR medium was prepared by mixing 1 vol. $3 \%$ agar solution in water (autoclaved for $15 \mathrm{~min}$ at $120^{\circ} \mathrm{C}$ and cooled to $60{ }^{\circ} \mathrm{C}$ ) with 1 vol. UHT (ultra high temperature-treated) milk that contained $10 \mathrm{~g}$ filter-sterilized yeast extract $1^{-1}$ and $10 \mathrm{~g}$ filtersterilized glucose $1^{-1}$ and was acidified to $\mathrm{pH} 5 \cdot 4$ with acetic acid. All strains were cultivated and maintained on MLR medium unless indicated otherwise. Bacteriological purity was checked by plating and examining living and Gramstained cells. Fourteen isolates were selected for further research. Sources of the new isolates studied and the type strains of L. kefirgranum and L. kefiranofaciens are given in Table 1.

Growth characteristics and colony morphology were investigated after $7-14$ days incubation at 25 or $30^{\circ} \mathrm{C}$ 
Table 1. Strains studied

Abbreviations: ATCC, American Type Culture Collection, Manassas, VA, USA; EXT, Danone Vitapole collection of micro-organisms, Palaiseau, France; JCM, Japan Collection of Microorganisms, the Institute of Physical and Chemical Research (RIKEN), Saitama, Japan; LMG, BCCM/LMG Bacteria Collection, Laboratorium voor Microbiologie, Ghent University, Ghent, Belgium; R, Research Collection Laboratorium voor Microbiologie, Ghent University, Ghent, Belgium.

\begin{tabular}{|c|c|}
\hline Species/strain & Source, place and year of isolation ${ }^{\star}$ \\
\hline \multicolumn{2}{|l|}{ L. kefiranofaciens: } \\
\hline LMG $19149^{\mathrm{T}}=\mathrm{JCM} 6985^{\mathrm{T}}=\mathrm{ATCC} 43761^{\mathrm{T}}$ & Kefir grains \\
\hline $\mathrm{R}-12937=\mathrm{EXT} 2.139$ & Kefir grain 16, France, 1999 \\
\hline $\mathrm{R}-14240=\mathrm{EXT} 2.143$ & Kefir grain 15, France, 1999 \\
\hline $\mathrm{R}-14242=\mathrm{EXT} 2.145$ & Kefir grain 14, France, 1999 \\
\hline $\mathrm{R}-14243=\mathrm{EXT} 2.146$ & Kefir grain 18, France, 1999 \\
\hline $\mathrm{R}-14244=\mathrm{EXT} 2.147$ & Kefir grain 8, France, 1999 \\
\hline $\mathrm{R}-14245=\mathrm{EXT} 2.148$ & Kefir grain 3, France, 1999 \\
\hline $\mathrm{R}-14703=\mathrm{EXT} 2.187$ & Kefir grain 9, France, 1999 \\
\hline \multicolumn{2}{|l|}{ L. kefirgranum: } \\
\hline LMG $15132^{\mathrm{T}}=\mathrm{JCM} 8572^{\mathrm{T}}$ & Kefir grains, Copenhagen, Denmark \\
\hline $\mathrm{R}-12929=\mathrm{EXT} 2.86$ & Kefir grain 16, France, 2000 \\
\hline $\mathrm{R}-13043=\mathrm{EXT} 2.93$ & Kefir grain 3, France, 2000 \\
\hline $\mathrm{R}-14331=\mathrm{EXT} 2.130$ & Kefir grain 15, France, 2000 \\
\hline $\mathrm{R}-14334=\mathrm{EXT} 2.133$ & Kefir grain 8, France, 2000 \\
\hline $\mathrm{R}-14340=\mathrm{EXT} 2.153$ & Kefir grain 14, France, 1999 \\
\hline $\mathrm{R}-14343=\mathrm{EXT} 2.156$ & Milk fermented with kefir grain 9, France, 1999 \\
\hline $\mathrm{R}-14344=\mathrm{EXT} 2.157$ & Canadian commercial kefir, France, 1999 \\
\hline
\end{tabular}

${ }^{\star}$ Kefir grains 3, 8, 9, 16 and 18 originated from different towns or villages of the Caucasus; grains 14 and 15 originated from the same village. They were used for home-made kefir and, from what the household could remember, they had been propagated constantly in the house and did not originate from a dairy factory.

under anaerobic conditions. Colonies of the 14 new isolates showed two very distinct morphological characteristics or morphotypes: seven strains (R-12929, R-13043, R-14331, R-14334, R-14340, R-14343 and R-14344) formed white, dry, compact, dull, bulging colonies, a morphotype similar to that of L. kefirgranum LMG $15132^{\mathrm{T}}$. The second group of seven strains (R-12937, R-14240, R-14242, R-14243, R-14244, R-14245 and R-14703) formed transparent, glossy, convex, extremely slimy colonies, similar to those of L. kefiranofaciens LMG $19149^{\mathrm{T}}$. Production of large amounts of polysaccharides is typical of $L$. kefiranofaciens and is suggested to be an important property in kefir grain formation (Takizawa et al., 1998).

Carbohydrate fermentation tests were carried out by using API $50 \mathrm{CH}$ galleries, following the instructions of the manufacturer (bioMérieux). Strains were cultivated for 4 days at $25^{\circ} \mathrm{C}$ under anaerobic conditions in MRSfpH5 4 [MRS medium (Difco), acidified to $\mathrm{pH} 5 \cdot 4$ with acetic acid and sterilized by filtration through $0.22 \mu \mathrm{m}$ filters]. The same grouping of the 14 isolates was found as was obtained on the basis of morphological criteria (see above). Strains that were assigned morphologically to L. kefirgranum tested positive for hydrolysis of aesculin and acid production from salicin and trehalose, whereas all strains with the L. kefiranofaciens morphotype tested negative for these features. High overall correspondence was obtained with the original species descriptions (Takizawa et al., 1994, 1998; Fujisawa et al., 1988). In these studies, acid production from salicin and trehalose was positive for most strains of L. kefirgranum and negative for all L. kefiranofaciens strains. Fermentation patterns of other carbohydrates did not provide additional distinguishing features between the taxa (see descriptions below).

All strains studied were investigated further by using PAGE of whole-cell proteins. Cultures were pre-cultivated for $24 \mathrm{~h}$ on MLR medium and were then transferred to MRSfpH5. 4 for $24 \mathrm{~h}$. Whole-cell protein extracts were prepared and SDS-PAGE was performed as described by Pot et al. (1994). Densitometric analysis, normalization and interpolation of the protein profiles and numerical analysis were performed by using the Gelcompar software package, versions 3.1 and 4.0, respectively (Applied Maths). Duplicate protein extracts were prepared, in order to check reproducibility of the growth conditions and preparation of the extracts. The correlation level for duplicate protein patterns was $r>0.94$. Whole-cell protein profiles of newly isolated strains were compared with patterns of the type strains of L. kefiranofaciens and L. kefirgranum (Fig. 1). All 


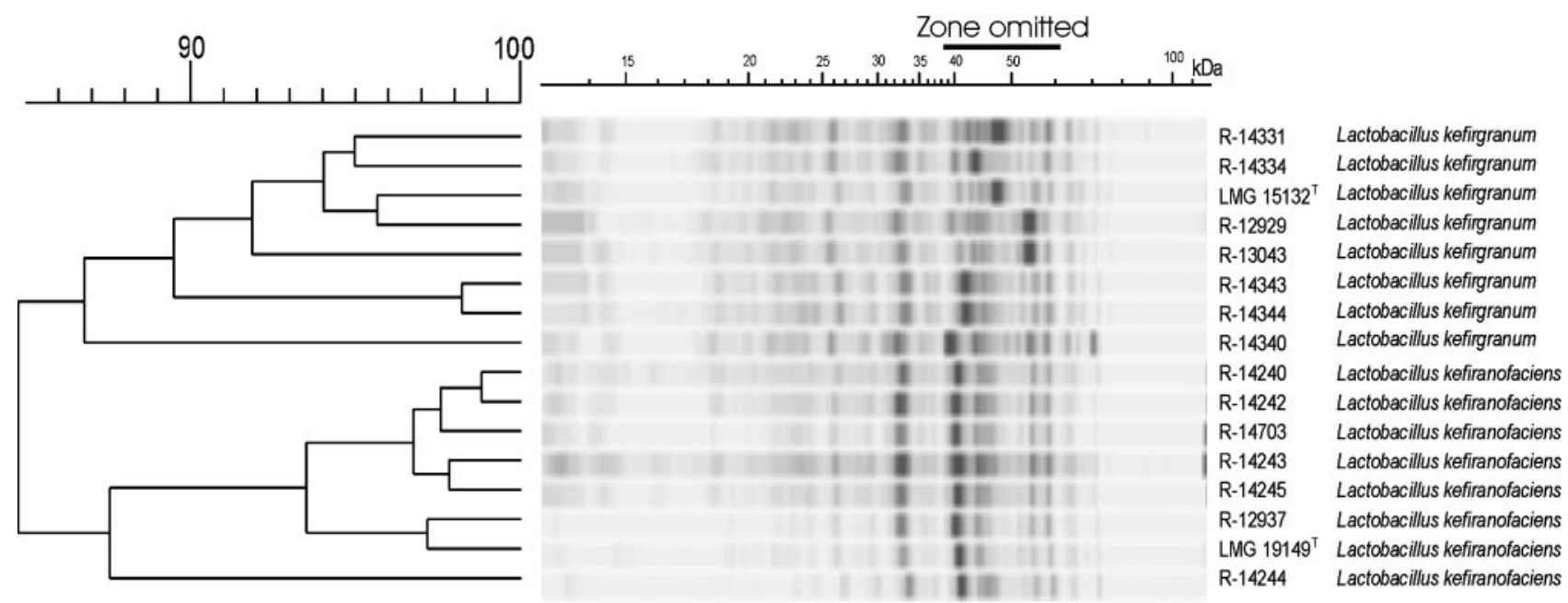

Fig. 1. Protein profiles and corresponding dendrogram derived from UPGMA linkage of the correlation coefficient $r$ (expressed as a percentage value for convenience) of L. kefiranofaciens and L. kefirgranum strains.

strains that were assigned phenotypically to L. kefiranofaciens showed a very similar profile to that of the type strain, whereas strains with the L. kefirgranum phenotype could be differentiated visually from each other by a varying position of a dominant protein band with a molecular mass of $38-60 \mathrm{kDa}$ (Fig. 1). The latter dense band largely influenced the numerical analysis; both taxa clustered separately and PAGE could be used as a tool for differentiation only after omitting this variable region from the cluster analysis. Strain-specific variable dense bands in L. kefirgranum may indicate the presence of a surface (S)-layer on the outside of the bacteria, as was demonstrated previously for other species of the Lactobacillus acidophilus group (Boot et al., 1996).

The phylogenetic positions of two representative strains of each species, L. kefirgranum LMG $15132^{\mathrm{T}}$ and R-12929 and L. kefiranofaciens LMG $19149^{\mathrm{T}}$ and R-14703, were determined by $16 \mathrm{~S}$ rDNA sequence analysis. Genomic DNA was prepared according to the protocol of Niemann et al. (1997). 16S rDNA was amplified by using oligonucleotide primers that were complementary to highly conserved regions of bacterial 16S rRNA genes. The forward primer was $5^{\prime}$-AGAGTTTGATCCTGGCTCAG-3' (which hybridizes at positions 8-27, according to the Escherichia coli numbering system) and the reverse primer was $5^{\prime}$-AAGGAGGTGATCCAGCCGCA-3' (positions 1541-1522). PCR products were purified by using a QIAquick PCR Purification kit (Qiagen) according to the manufacturer's instructions. Purified PCR products were sequenced by using an ABI Prism BigDye Terminator Cycle Sequencing Ready Reaction kit and an Applied Biosystems 377 DNA sequencer, using the protocols of the manufacturer (Applied Biosystems). The eight sequencing primers used were listed by Coenye et al. (1999). Sequence assembly was performed by using the program AutoAssembler (Applied Biosystems).
Determined 16S rRNA gene sequences (a continuous stretch of $1516 \mathrm{bp}$ for all four strains tested) and sequences of strains that were retrieved from GenBank/EMBL were aligned and a phylogenetic tree was constructed by the neighbour-joining method, using the Bionumerics 3.50 software package (Applied Maths). Unknown bases were discarded from the analysis. Bootstrapping analysis was undertaken to test the statistical reliability of the topology of the neighbour-joining tree by using 500 bootstrap resamplings of the data (Fig. 2). Comparison of the four complete sequences revealed $100 \%$ similarity among all strains. Further comparison with sequences from GenBank/ EMBL classified the strains in the L. acidophilus group (Schleifer \& Ludwig, 1995), with Lactobacillus crispatus, Lactobacillus gallinarum, Lactobacillus hamsteri, Lactobacillus amylovorus, Lactobacillus amylolyticus, Lactobacillus intestinalis and L. acidophilus as nearest neighbours (95.6-97.7\% similarity).

DNA G $+C$ contents were determined for L. kefirgranum LMG $15132^{\mathrm{T}}$ and R-12929 and L. kefiranofaciens LMG $19149^{\mathrm{T}}$ and R-14703. Strains were grown for $24 \mathrm{~h}$ on MLR medium at $28^{\circ} \mathrm{C}$ under anaerobic conditions. Highmolecular-mass native DNA was extracted from 0.75$1.25 \mathrm{~g}$ cells (wet weight) by using the protocol described by Pitcher et al. (1989) with the following modifications: cell pellets (LMG $19149^{\mathrm{T}}$ and R-14703 received an additional washing step with $0 \cdot 1 \mathrm{M} \mathrm{NaOH}$ ) were washed with RS buffer $(0.15 \mathrm{M} \mathrm{NaCl}, 10 \mathrm{mM}$ EDTA, $\mathrm{pH} \mathrm{8.0)}$ and resuspended in a buffer $(10 \mathrm{mM}$ Tris/ $\mathrm{HCl}, 300 \mathrm{mM}$ EDTA, pH 8.0) that contained RNase $\left(200 \mu \mathrm{g} \mathrm{ml}^{-1}\right.$; Sigma), mutanolysin (200 $\mathrm{U} \mathrm{ml}^{-1}$; Sigma) and lysozyme $\left(25 \mathrm{mg} \mathrm{ml}^{-1}\right.$; Serva) and incubated for $1 \mathrm{~h}$ at $37^{\circ} \mathrm{C}$. At 15 min before the addition of GES reagent, proteinase $\mathrm{K}$ (200 $\mu \mathrm{g} \mathrm{ml}^{-1}$; Merck) was added to the mixture. DNA was dissolved in $0 \cdot 1 \times \operatorname{SSC}(0 \cdot 15 \mathrm{M} \mathrm{NaCl}, 0 \cdot 015 \mathrm{M}$ citric acid, 


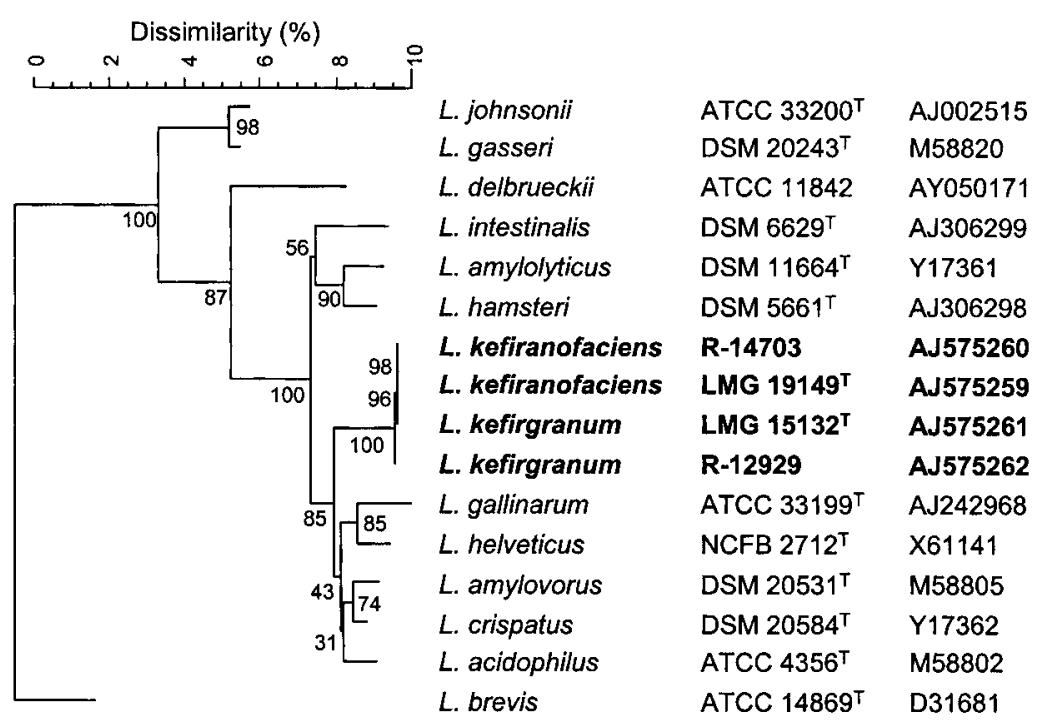

Fig. 2. Distance matrix tree showing the phylogenetic relationships of $L$. kefiranofaciens, L. kefirgranum and other reference species that belong to the $L$. acidophilus group, based on $16 \mathrm{~S}$ rDNA sequence comparisons. Lactobacillus brevis was used as the outgroup and bootstrap (stability) values are indicated at branch-points (from 500 tree replications).
$0 \cdot 4 \mathrm{M} \mathrm{NaOH}, \mathrm{pH} 7 \cdot 0$ ) to obtain a concentration of $0 \cdot 3-$ $0.8 \mathrm{mg} \mathrm{ml}^{-1}$. For determination of the DNA G $+\mathrm{C}$ content, DNA was degraded enzymically into nucleosides and separated by HPLC, as described by Mesbah et al. (1989). The measured DNA G + C contents for L. kefirgranum LMG $15132^{\mathrm{T}}$ and R-12929 were $38 \cdot 2$ and $38 \cdot 1 \mathrm{~mol} \%$, respectively, which conforms to the range of $34 \cdot 3-38 \cdot 6 \mathrm{~mol} \%$ reported for the species (the lowest aberrant value was found for only one strain; Takizawa et al., 1994). For $L$. kefiranofaciens LMG $19149^{\mathrm{T}}$ and R-14703, the measured DNA G $+\mathrm{C}$ contents were $37 \cdot 6$ and $37 \cdot 3 \mathrm{~mol} \%$, respectively; these values are somewhat higher than the reported values of 34.3-35.4 mol\% (Fujisawa et al., 1988) and 36.0$36.8 \mathrm{~mol} \%$ (Takizawa et al., 1994, 1998). This variation may be explained by the different procedures that were used for analysis: HPLC (present study) versus the thermal melting-point $\left(T_{\mathrm{m}}\right)$ method (Marmur \& Doty, 1962), which was used for data in the literature.

DNA-DNA hybridizations were performed between $L$. kefirgranum LMG $15132^{\mathrm{T}}$ and R-12929 and L. kefiranofaciens LMG $19149^{\mathrm{T}}$ and R-14703 (DNA was prepared as above). The microplate method was used, as described by Ezaki et al. (1989) and Goris et al. (1998), using an HTS7000 Bio Assay reader (Perkin Elmer) for fluorescence measurements. Biotinylated DNA was hybridized with unlabelled ssDNA, which was bound non-covalently to microplate wells. Hybridizations were performed at $36.1^{\circ} \mathrm{C}$ in a hybridization mixture that contained $2 \times$ SSC, $5 \times$ Denhardt's solution, $2.5 \%$ dextran sulphate, $50 \%$ formamide, $100 \mu \mathrm{g}$ denaturated salmon sperm DNA $\mathrm{ml}^{-1}$ and $1250 \mathrm{ng}$ biotinylated probe DNA ml${ }^{-1}$. DNA relatedness values are mean percentages, based on at least two independent hybridization experiments. Reciprocal reactions were performed and variation was within the limit of this method (Goris et al., 1998). Hybridization values between two representative strains of L. kefirgranum, LMG $15132^{\mathrm{T}}$ and R-12929, yielded a binding value of $86 \%$.
Two L. kefiranofaciens strains, LMG $19149^{\mathrm{T}}$ and R-14703, were also closely related, with a DNA binding value of $96 \%$. When determining DNA relatedness among strains of both species, high binding values (79-91\%) were obtained, indicating clearly that both taxa belong to the same genospecies. The latter results contradict those given by Takizawa et al. (1994), who reported a low homology of $30 \%$ between the type strains of both taxa. Unfortunately, these authors performed only a single hybridization experiment between one strain of each species. In a later study by the same authors on the biodiversity of kefir grains (Takizawa et al., 1998), the same DNA-DNA binding value of $30 \%$ is given between the type strain of L. kefiranofaciens and 'isolate no. 41', which belonged to L. kefirgranum. We observed, however, that the DNA homology data given in the latter paper are a duplication of results given in the earlier paper (Takizawa et al., 1994) and do not provide additional confirmation of low homology between L. kefiranofaciens and L. kefirgranum. Comparison of data from Takizawa et al. (1998) with their earlier paper (Takizawa et al., 1994) is confusing, as the same data were reported without making reference to the original strain designations and without indication of the type strain of L. kefirgranum.

Morphological and phenotypic data from the present study confirm that we are working with the authentic type strains and well-characterized isolates of both L. kefiranofaciens and L. kefirgranum. Phylogenetic and genotypic data on the type and other representative strains indicate clearly that both taxa belong to the same genospecies and are synonyms. According to nomenclatural rules, the name of the earlier synonym, i.e. L. kefiranofaciens, is retained, whereas the name of the later synonym, i.e. L. kefirgranum, becomes its heterotypic synonym. Due to the very different morphological features of both taxa, linked with their suggested specific roles in kefir grain formation and the availability of a number of differentiating 
phenotypic features, we propose that $L$. kefirgranum should be reclassified as a subspecies of $L$. kefiranofaciens. Below, we give an emended description of $L$. kefiranofaciens and propose a description of two novel subspecies, L. kefiranofaciens subsp. kefiranofaciens subsp. nov. and L. kefiranofaciens subsp. kefirgranum subsp. nov., based on data from the literature (Fujisawa et al., 1988; Takizawa et al., 1994, 1998) and from the present study.

\section{Emended description of Lactobacillus kefiranofaciens Fujisawa et al. 1988}

Lactobacillus kefiranofaciens (ke.fi.ra.no.fa'ci.ens. N.L. n. kefiran a polysaccharide of kefir grain, kefiran; L. v. facio produce; N.L. part. adj. kefiranofaciens kefiran-producing).

Gram-positive, non-motile, non-spore-forming rods that are generally $0 \cdot 5-1 \cdot 2 \times 3 \cdot 0-20 \mu \mathrm{m}$ in size and occur singly, in pairs or occasionally in short chains. Colony morphology is subspecies-dependent (see below). There is weak or no growth at $15^{\circ} \mathrm{C}$ and no growth at $45^{\circ} \mathrm{C}$. Facultatively anaerobic and produces DL-lactic acid homofermentatively. Catalase is not produced. Hydrolysis of aesculin is variable. Gas is not produced from glucose or gluconate. Arginine is not deaminated. Milk is curdled. Acid is produced from galactose, D-glucose, D-fructose and lactose, but not from adonitol, D-arabinose, L-arabinose, D-arabitol, L-arabitol, dulcitol, erythritol, D-fucose, L-fucose, gluconate, 2-ketogluconate, 5-ketogluconate, methyl $\alpha$-D-glucoside, glycerol, glycogen, inositol, D-lyxose, mannitol, D-mannose, methyl $\alpha$-D-mannoside, melezitose, rhamnose, ribose, sorbitol, L-sorbose, starch, D-tagatose, xylitol, D-xylose, $\mathrm{L}$-xylose or methyl $\beta$-xyloside. Acid production from amygdalin, arbutin, cellobiose, $\beta$-gentiobiose, $N$-acetylglucosamine, inulin, maltose, melibiose, D-raffinose, salicin, sucrose, trehalose and D-turanose is strain-dependent. DNA G + C content is $37 \cdot 3-38 \cdot 2 \mathrm{~mol} \%$ (HPLC) or $34 \cdot 3-38 \cdot 6 \mathrm{~mol} \%\left(T_{\mathrm{m}}\right)$.

The type strain is LMG $19149^{\mathrm{T}}\left(=\mathrm{JCM} 6985^{\mathrm{T}}=\right.$ ATCC $\left.43761^{\mathrm{T}}\right)$. The habitat of the species is kefir grains.

\section{Description of Lactobacillus kefiranofaciens subsp. kefiranofaciens subsp. nov.}

The description is as that for the species, with the following additional characteristics. Cells are capsulated. On modified KPL agar ( $\mathrm{pH} 5.5$ ) at $30^{\circ} \mathrm{C}$ after 10 days, colonies are circular or irregular, $0 \cdot 5-3.0 \mathrm{~mm}$ in diameter, convex, transparent to translucent, white, smooth to rough and ropy. On MLR medium under anaerobic conditions after 7-14 days incubation at 25 or $30^{\circ} \mathrm{C}$, colonies are transparent, glossy, convex and extremely slimy. Large amounts of polysaccharides are produced. No growth occurs at $15^{\circ} \mathrm{C}$. Hydrolysis of aesculin is negative. Acid is produced from sucrose, but not from amygdalin, arbutin, cellobiose, $\beta$-gentiobiose, inulin, salicin, trehalose or D-turanose. Acid production from $\mathrm{N}$-acetylglucosamine, maltose, melibiose and D-raffinose is strain-dependent.
The type strain is LMG $19149^{\mathrm{T}}\left(=\mathrm{JCM} 6985^{\mathrm{T}}=\mathrm{ATCC}\right.$ $\left.43761^{\mathrm{T}}\right)$.

\section{Description of Lactobacillus kefiranofaciens subsp. kefirgranum subsp. nov.}

Lactobacillus kefirgranum (ke.fir.gra' num. Turkish n. kefir Caucasian sour milk; L. n. granum grain; N.L. adj. kefirgranum kefir grain).

The description is as for the species, with the following additional characteristics. On R-CW agar (Kojima et al., 1993 ) at $30^{\circ} \mathrm{C}$ for 5 days, colonies are $0.5-3.0 \mathrm{~mm}$ in diameter, circular to irregular, convex, opaque, white and smooth to rough. On MLR medium under anaerobic conditions after $7-14$ days incubation at 25 or $30^{\circ} \mathrm{C}$, colonies are white, dry, compact, dull and bulging. Flocculus or powdery sediment is formed in broth. Weak growth occurs at $15^{\circ} \mathrm{C}$. Hydrolysis of aesculin is positive. Acid is produced from maltose and melibiose and, for nearly all strains, also from D-raffinose, salicin, sucrose and trehalose. Acid production from amygdalin, arbutin, cellobiose, $\beta$-gentiobiose, $\mathrm{N}$-acetylglucosamine, inulin and D-turanose is strain-dependent.

The type strain is LMG $15132^{\mathrm{T}}\left(=\mathrm{JCM} 8572^{\mathrm{T}}\right)$.

\section{Acknowledgements}

This research was co-financed by the Prime Minister's Services Federal Office for Scientific, Technical and Cultural Affairs, Belgium. We thank Frederique Lambre, Penka Moncheva and the technical team of BCCM/LMG for their technical assistance.

\section{References}

Boot, H. J., Kolen, C. P. A. M., Pot, B., Kersters, K. \& Pouwels, P. H. (1996). The presence of two S-layer-protein-encoding genes is conserved among species related to Lactobacillus acidophilus. Microbiology 142, 2375-2384.

Coenye, T., Falsen, E., Vancanneyt, M., Hoste, B., Govan, J. R. W., Kersters, K. \& Vandamme, P. (1999). Classification of Alcaligenes faecalis-like isolates from the environment and human clinical samples as Ralstonia gilardii sp. nov. Int J Syst Bacteriol 49, 405-413.

Ezaki, T., Hashimoto, Y. \& Yabuuchi, E. (1989). Fluorometric deoxyribonucleic acid-deoxyribonucleic acid hybridization in microdilution wells as an alternative to membrane filter hybridization in which radioisotopes are used to determine genetic relatedness among bacterial strains. Int J Syst Bacteriol 39, 224-229.

Fujisawa, T., Adachi, S., Toba, T., Arihara, K. \& Mitsuoka, T. (1988). Lactobacillus kefiranofaciens sp. nov. isolated from kefir grains. Int J Syst Bacteriol 38, 12-14.

Goris, J., Suzuki, K., De Vos, P., Nakase, T. \& Kersters, K. (1998). Evaluation of a microplate DNA-DNA hybridization method compared with the initial renaturation method. Can J Microbiol 44, 1148-1153.

Halle, C. (1992). Etude taxonomique de la microflore du kéfir lacté et mise en évidence d'une interaction entre les bactéries lactiques et les levures dans le lait. $\mathrm{PhD}$ thesis, l'Université de Nantes (in French). 
Halle, C., Leroi, F., Dousset, X. \& Pidoux, M. (1994). Les kéfirs: des associations bactéries-levures. In Bactéries Lactiques, vol. 2, pp. 169182. Edited by H. de Roissart \& F. M. Luquet. Uriage, France: Lorica (in French).

Hirota, T. (1987). Microbiological studies on kefir grains. Rep Res Lab Snow Brand Milk Prod Co 84, 67-128.

Kandler, O. \& Kunath, P. (1983). Lactobacillus kefir sp. nov., a component of the microflora of kefir. Syst Appl Microbiol 4, 286-294.

Kojima, S., Takizawa, S., Tamura, S., Fujinaga, S., Benno, Y. \& Nakase, T. (1993). A new medium for the isolation of lactobacilli from kefir grains. Biosci Biotechnol Biochem 57, 119-120.

Marmur, J. \& Doty, P. (1962). Determination of the base composition of deoxyribonucleic acid from its thermal denaturation temperature. J Mol Biol 5, 109-118.

Mesbah, M., Premachandran, U. \& Whitman, W. B. (1989). Precise measurement of the $\mathrm{G}+\mathrm{C}$ content of deoxyribonucleic acid by high-performance liquid chromatography. Int J Syst Bacteriol 39, 159-167.

Mukai, T., Toba, T., Itoh, T. \& Adachi, S. (1990). Structural investigation of the capsular polysaccharide from Lactobacillus kefiranofaciens K1. Carbohydr Res 204, 227-232.

Niemann, S., Pühler, A., Tichy, H.-V., Simon, R. \& Selbitschka, W. (1997). Evaluation of the resolving power of three different DNA fingerprinting methods to discriminate among isolates of a natural Rhizobium meliloti population. J Appl Microbiol 82, 477-484.

Pitcher, D. G., Saunders, N. A. \& Owen, R. J. (1989). Rapid extraction of bacterial genomic DNA with guanidium thiocyanate. Lett Appl Microbiol 8, 151-156.

Pot, B., Vandamme, P. \& Kersters, K. (1994). Analysis of electrophoretic whole-organism protein fingerprints. In Chemical Methods in Prokaryotic Systematics, pp. 493-521. Edited by M. Goodfellow \& A. G. O'Donnell. Chichester, UK: Wiley.

Schleifer, K. H. \& Ludwig, W. (1995). Phylogeny of the genus Lactobacillus and related genera. Syst Appl Microbiol 18, 461-467.

Takizawa, S., Kojima, S., Tamura, S., Fujinaga, S., Benno, Y. \& Nakase, T. (1994). Lactobacillus kefirgranum sp. nov. and Lactobacillus parakefir sp. nov., two new species from kefir grains. Int J Syst Bacteriol 44, 435-439.

Takizawa, S., Kojima, S., Tamura, S., Fujinaga, S., Benno, Y. \& Nakase, T. (1998). The composition of the Lactobacillus flora in kefir grains. Syst Appl Microbiol 21, 121-127.

Toba, T. (1987). Fermented milks produced with mesophilic lactic acid bacteria. Kefir and Scandinavian ropy sour milk. Jpn J Dairy Food Sci 36, 235-244.

Yokoi, H., Watanabe, T., Fujii, Y., Mukai, T., Toba, T. \& Adachi, S. (1991). Some taxonomical characteristics of encapsulated Lactobacillus sp. KPB-167B isolated from kefir grains and characterization of its extracellular polysaccharide. Int J Food Microbiol 13, 257-264. 